\title{
A cidade e as serras: a odisséia bufa de um herói moderno
}

\author{
Maria Edith Maroca de Avelar Rivelli de Oliveira \\ Universidade Federal de Minas Gerais
}

\begin{abstract}
De um lado tiveram acesso à vida forças industriais e científicas de que nenhuma época anterior, na história da bumanidade, chegara a suspeitar. De outro lado, estamos diante de sintomas de decadência que ultrapassam em muito os horrores dos últimos tempos do Império Romano. Em nossos dias, tudo parece estar impregnado do seu contrário. O maquinário, dotado do maravilhoso poder de amenizar e aperfeiçoar o trabalho humano, só faz, como se observa, sacrificá-lo e sobrecarregá-lo. As mais avançadas fontes de saúde, graças a uma misteriosa distorção, tornaram-se fontes de penúria. As conquistas da arte parecem ter sido conseguidas com a perda do caráter. Na mesma instância em que a bumanidade domina a natureza, o bomem parece escravizar-se a outros homens ou à sua própria infâmia. Até a pura luz da ciência parece incapaz de brilhar senão no escuro pano de fundo da ignorância. Todas as nossas invençôes e progressos parecem dotar de vida intelectual às forças materiais, estupidificando a vida humana ao nivel da força material. (Karl Marx, "Speech at the anniversary of the People's Paper")
\end{abstract}

\section{Introdução}

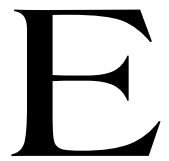

m tempos de Pós-modernidade presumida e dúvidas existenciais coletivas, visionária nos parece esta obra de Eça de Queiroz, A Cidade e as Serras. Centenária, mantém o frescor pela qualidade da prosa queiroziana e por um certo caráter profético do moteto de cansaço da Modernidade, tema da obra e motor da Saga de salvação do personagem principal, Jacinto.

Quer nos parecer que a genialidade do Eça deste A Cidade e as Serras predizia-nos, através das aventuras nada galantes deste personagem, as 
desventuras próprias de nossa época, a desilusão moderna e a tentativa inútil de retorno ao útero mítico o qual, se ao Jacinto, como herói Moderno é franqueado para que se salve, para nós inexiste como alternativa.

O artigo se propõe, portanto, a uma leitura d'A Cidade e as Serras, em que se ressaltará a pertinência clarividente de sua crítica à Modernidade uma vez que, tendo sido a obra produzida em período de auge da mesma, prenunciava já sua exaustão, que hoje vivemos.

\section{Eça e seus moinhos}

A crítica da Modernidade, em Eça, parte já da opção estilística. Para melhor expor suas idéias, ele opta, em $A$ cidade e as serras, por um retorno à tradição epopeica ainda que numa modalidade bufa, em revisita a Cervantes, narrando as desventuras de um herói que acredita veementemente nas idéias de seu tempo: Jacinto, o "Príncipe da grã-ventura". Acompanhando-o como "fiel escudeiro", o Zé Fernandes que, em proporção direta a Sancho Pança, tem a responsabilidade de resgatar o bom senso do herói. Há também simulacros de Dulcinéia, mas sem a força ideal daquela. Mais até que Dom Quixote, é pelas idéias que Jacinto vive.

Paralelamente a este caráter paródico, o que mais nos impressiona nesta obra é a atualidade do texto, pleno de significados na vivacidade de sua crítica à Modernidade e que se aproxima bastante de algumas das vertentes atuais da Crítica Pós-moderna. Dentro deste contexto, parecenos que a negativa da Modernidade teria, inclusive, justificado a "ressurreição" do grande anti-herói moderno, o Dom Quixote.

Um tal retorno, tanto ao personagem, quanto à estilística que o reveste - recriados na obra - nos levam a inferir em Eça predições de posturas Pós-modernas que se encontrariam bastante bem representadas pelo comportamento de Jacinto, um "proto-Pós-moderno". Esta busca antiModerna nos é explicitada por Eça, através de seu personagem Zé Fernandes, quando este afirma seu desejo de um futuro em que

(...) outros homens, com uma compreensão mais pura e exata da vida e da felicidade, percorreriam, como eu, longas salas, atulhadas com os instrumentos da super-civilização, e, como eu, encolheriam desdenhosamente os ombros ante a grande ilusão que findara, agora para sempre inútil, arrumada como um grande lixo histórico, guardado debaixo da lona. ${ }^{1}$

\footnotetext{
${ }^{1}$ QUEIROS, 1978. p. 181-182.
} 
Cansado da euforia fútil da Modernidade, percebida por ele como vazia e esvaziadora de sentido, Eça produz um Jacinto/Quixote que duelará contra os "moinhos de vento" da Modernidade, compartilhando com o Quixote de Cervantes a preferência pela contramão na Sociedade; em contrário àquele, porém, Jacinto se tornará o único sadio em meio a uma sociedade absolutamente insana.

Se Dom Quixote representava, em sua loucura, a opção pela literatura e o idealismo em detrimento da realidade empírica vivida pela sociedade que o rodeia, Jacinto se apresentará como um exótico caçador de lucidez em meio a uma sociedade embriagada por uma loucura que se define à obra como sendo a Modernidade.

Portanto, assim se separam Dom Quixote e Jacinto. Aquele, após viver suas desventuras grotescas em nome de um ideal insano, termina por renegar suas sandices, o que fatalmente o levará à morte. Dom Quixote não sobrevive em um mundo real.

Jacinto fará o caminho oposto: definhando calmamente em um mundo aparentemente real, salvar-se-á fugindo da sociedade abstrata e estéril em que vive, rumo a um mundo mais empírico e absolutamente diferente da alucinação coletiva em que se perdia na cidade.

A retirada estratégica de Jacinto do meio urbano supercivilizado em direção ao mundo antiquado e retrógrado, em que se reencontrará com o espírito da natureza e do humano, nos remetem ao relato de Marshall Bermann sobre os Pós-modernos atuais.

A crítica do maravilhamento irracional provocado pela Modernidade é uma das tônicas de Tudo que é sólido desmancha no ar - a aventura da Modernidade. Nesta obra Berman propõe uma revisão crítica destes primórdios da Modernidade, numa perspectiva bastante próxima àquela do Jacinto, 100 anos antes. O livros nos descreve proposições de autores hodiernos, denominados Pós-modernos, em que podemos perceber consonâncias importantes com a crítica queiroziana, como bem ilustra o trecho que se segue

Se a serpente modernista pudesse ser expelida do Éden moderno, espaço, tempo e cosmo poderiam reordenar-se. Aí, então, presume-se, uma idade de ouro tecnopastoral surgiria, e homens e mulheres poderiam aninhar-se, paziguados, para todo o sempre. ${ }^{2}$

${ }^{2}$ BERMAN, 1989. p. 30. 
Tal perspectiva se irmana àquela do Jacinto, porém com uma ressalva: as proposições queirozianas se encontravam perfeitamente pertinentes em sua época, sendo que hoje requerem uma adequação. Não podemos mais voltar ao útero da natureza, como Jacinto, pois que uma tal perspectiva hoje se torna inviável.

Mas podemos seguir sua trilha de crítica e questionamento, como nos propõe Berman, em busca não mais da Anti-modernidade, mas da própria, sob cujos destroços reside o "nosso lugar possível". Ela sim, seria para nós, Jacintos Pós-modernos, a casa para a qual retornar, como nos afirma Berman

Eles [os modernistas do passado] podem iluminar as forças contraditórias e as necessidades que nos inspiram e nos atormentam: nosso desejo de nos enraizarmos em um passado social e pessoal coerente e estável, e nosso insaciável desejo de crescimento (...) crescimento que destrói as paisagens físicas e sociais do nosso passado e nossos vínculos emocionais com esses mundos perdidos; (...) nosso desejo de sólidos e claros valores em função dos quais viver e nosso desejo de abarcar todas as ilimitadas possibilidades de vida e experiência modernas, que oblitera todos os valores; (...) Experiências como essas nos unem ao mundo moderno do século XIX $(\ldots)^{3}$

Acompanhando Berman, destacamos nosso retorno a Eça portanto, pela importância de sua crítica à Modernidade da qual somos os órfãos e para que possamos, jacinticamente, perceber melhor as raízes de nossas esperanças e agruras.

\section{A cidade e as serras}

Dentro da perspectiva acima delineada, queremos poder perceber nesta obra de Eça uma problemática centrada no embate dialético entre duas possibilidades do viver humano, sendo que uma seria aquela denunciada pela obra: a da super-civilização, compreendida aí como "fascinação pelo simulacro" e representada pela Cidade e uma outra possibilidade, as Serras, proposição queiroziana de solução para o problema representado pela primeira e configurado no livro como um

\footnotetext{
${ }^{3}$ QUEIROZ, 1978. p. 34.
} 
"empirismo ilustrado", sendo também personificadas pelo eterno debate entre duas personagens o Jacinto (representante da Cidade) e o Zé Fernandes, que encarna as Serras.

Se considerarmos como modelar a Odisséia - citação não fortuita, uma vez que, em sua retirada para as Serras, este é um dos dois livros que Jacinto elege como necessário, dentro de sua biblioteca de 40 mil volumes, sendo o outro o Dom Quixote de Cervantes - poderíamos dizer que Paris representaria a feiticeira "Circe" (personagem da Odisséia), que mantém Ulisses/Jacinto encantado e longe de seu verdadeiro lar: as Serras. Tal encantamento se perceberia, no romance, pela vida fútil que lhe é proporcionada pela Modernidade e que longe de satisfazê-lo, mantémno sempre insatisfeito porque distante de sua real natureza.

A aventura se dividirá, portanto, em duas partes: a primeira se ocupará de nos dar a perceber, pelas desventuras de Jacinto X Modernidade, as ilusões em que este teria se enredado, enfeitiçado pela magia tecnológica, mais que por qualquer mulher. Na Segunda parte, o Jacinto será "transplantado" para as Serras, onde personificará a possibilidade de uma verdadeira felicidade, mais real. Passemos, portanto, à primeira parte.

\subsection{O cavaleiro da triste figura}

O romance nos apresenta o tom iniciático da epopéia do jovem serrano, Zé Fernandes, que, acompanhando seu amigo citadino, o Jacinto, pelas aventuras burlescas da cidade grande, durante um bom período de tempo em que tais atividades irão levar o Jacinto a fenecer no fastio da fútil vida moderna.

Logo, Jacinto nos é apresentado em sua posição de desenraizado (Queiroz, 1975)

Nasceu num palácio, com cento e vinte contos de renda em terras de semeadura, de vinhedo, de cortiça e de olival. No Alentejo, pela Estremadura, através das duas Beiras, (...) delimitavam os campos desta velha família que já entulhava o grão e plantava cepa em tempos delrei Dom Dinis. (...)Mas o palácio onde Jacinto nascera, e onde sempre habitara, era em Paris, nos campos Elísios, n.. $202 .^{4}$

${ }^{4}$ QUEIROZ, 1978. p. 3. 
Portanto, desde o início nos é apresentado um Jacinto que vive de forma absolutamente desenraizada: sua renda, proveniente da agricultura numa terra distante, é-lhe absolutamente estranha. Suas raízes familiares, tão profundamente arraigadas em Portugal, nada lhe dizem. Jacinto é uma flor de estufa, vivendo uma vida artificial.

Esta artificialidade terá seu preço. Pela primeira impressão que causa em Zé Fernandes, Jacinto nos é apresentado como no auge de sua natureza viril, desenvolvendo-se de acordo com sua natureza genética

Este delicioso Jacinto fizera então vinte e três anos, e era um soberbo moço em que reaparecera a força dos velhos Jacintos rurais. Só pelo nariz, afilado, com narinas quase transparentes, de uma mobilidade inquieta, como se andasse fariscando perfumes, pertencia às delicadezas do século XIX. ${ }^{5}$

Jacinto, nos é descrito então como o serrano que ignora suas raízes, e insiste em fazer da civilização sua profissão de fé. Seu credo se resume em poucas palavras "Claro é portanto que nos devemos cercar de civilização nas máximas proporções para gozar nas máximas proporções a vantagem de viver." ${ }^{6}$

Zé Fernandes, o espírito das Serras encarnado, serena e firmemente cônscio de quem é e de suas crenças, observa as oscilações de Jacinto e seu "Grand Monde"de novidade em novidade, sem que nada jamais passe de moda, como nos ilustra bastante bem o diálogo que se segue

- “(..) Reinava Wagner e a mitologia ética, e o Raganarock, e as Normas... muito pré-rafaelismo também, e Montagna, e Fra-Angelico... Em moral, o renanismo. (...)

- (...) já o renanismo passara, tão esquecido como o cartesianismo ...

- Tu ainda és do tempo do culto do eu?

- Pois bem, logo depois foi o Hartmannismo, o inconsciente. Depois o nietszchianismo, o feudalismo espiritual ... depois reinou o tolstoismo, um furor imenso de renunciamento neocenobítico. (...) Depois veio o emersonismo ... mas a praga cruel foi o ibsenismo! Enfim, meu filho, uma Babel de éticas e estéticas. Paris parecia demente. Já havia uns desgarrados que tendiam par ao Luciferismo. E amiguinhas nossas, coitadas, iam

${ }^{5}$ QUEIROZ, 1978. p. 11

${ }^{6}$ QUEIROZ, 1978. p. 08. 
descambando para o falismo, uma moxinifada místico-brejeira, pregada por aquele pobre La Carte que depois se fez monge branco e que anda pelo deserto ... (...) E uma tarde, de repente, toda essa massa se precipita com ânsia para o ruskinismo! (negrito do autor)"”

Esta Babel de Éticas e Estéticas, que nos é traçada pelo diálogo acima, tem por objetivo nos descrever, com algum exagero e fino humor negro, as veleidade das Modernidade, em que se segue qualquer um e qualquer coisa, fervorosamente por rápidos instantes, enquanto não surge a nova vaga que a substituirá.

Perceba-se que neste redemoinho humano, mesmo os líderes se encontram perdidos, como nos ilustra a personagem do ex-lider filosófico orgiástico que se torna monge e parte para o deserto.

No momento de seu encontro com Zé Fernandes, Jacinto professa o positivismo, para cuja crença tenta arrebanhar o amigo. Este, porém, mantém-se a uma distância segura do fanatismo, percebendo todos os artefatos ultramodernos com que Jacinto tenta encantá-lo como "uma mecânica suntuosa, aparelhos, lâminas, rodas, tubos, engrenagens, hastes, friezas, rigidezas de metais ...". ${ }^{8}$ Para o Zé Fernandes, são apenas isso, frieza, rigidez, metal. Falta-lhes vida, alma, sentido. Não se dispõe, absolutamente, a substituir o empirismo pastoril de sua vida nas serras, pela frieza tecnicista da vida e das relações na cidade.

Para que se convença de sua opção, basta-lhe ver o definhar de Jacinto. Em meio à parafernália e a multidão, Jacinto é uma flor que flana desenraizada. Herdeiro de imensa fortuna em Portugal - de onde fugira o avô, durante a revolução - Jacinto sobrevive pródiga e entediadamente em Paris, às expensas da riqueza das Serras, que ignora.

Formatado pelo positivismo, confunde felicidade com erudição e tecnologia. Sua sede insaciável destes elementos levam-no a colecionar milhares de livros que não lê e uma série interminável de artefatos que nem ao menos funcionam. Por entre tais artefatos desancados pelo autor, como uma máquina de abotoar ceroulas e outra de abrir correspondência encontram-se, curiosamente, tecnologias que nos são caras hoje, como a luz elétrica e a água quente, ironizadas pelo autor como o são todas as outras.

Em meio a tanta fartura, Jacinto morre de sede, tendo à frente águas carbonatadas, aromatizadas, em profusão; que, porém, jamais o saciam.

\footnotetext{
${ }^{7}$ QUEIROZ, 1978. p. 66.

${ }^{8}$ QUEIROZ, 1978. p. 15.
} 
É assíduo a banquetes, sem que sinta fome por anos. Tais revelações, quando relatadas a Zé Fernandes, atordoam-no, uma vez que contradizem a bem-aventurança que parecia associada à civilização. Ele esperava "na convivência de um tão grande iniciado como Jacinto, (...) [compreender] todas as finuras e todos os poderes da civilização."

Cedo o serrano irá percebendo que nada nesta civilização traz substância e, portanto, saciedade. Tudo é falso, elaborado, irreal, e assim sem capacidade de satisfazer as reais necessidades humanas. Mesmo as pessoas perdem substância, como podemos perceber pela sua descrição de uma dama

(...) toda ela derramava uma sensação de macio e de fino. Eu teimosamente a considerava uma flor de civilização: - e pensava no secular trabalho que necessitara o terreno onde ela tão delicadamente brotara, já desabrochada, em pleno perfume, mais graciosa por ser flor de esforço e de estufa, e trazendo nas suas pétalas um não sei quê de desbotado e de antemurcho." ${ }^{10}$

De fausto em enfaro, o Jacinto, por fim, descamba para o ceticismo. Zé Fernandes define de maneira bastante prática a mudança do amigo: "Jacinto encontrara enfim na vida uma ocupação grata - maldizer a vida!"11 Mas mesmo este surto passará, e o vazio que se abate sobre Jacinto preocupa o Zé Fernandes. Neste ponto ficará a cargo da sobriedade do serrano, e do acaso, a responsabilidade de retornar o Jacinto ao seu habitat natural, e à sobriedade.

\section{2. $O$ fiel escudeiro}

Zé Fernandes, o narrador serrano, é o responsável pelo descentramento da perspectiva Jacíntica. Tendo principiado a aventura como discípulo a se iniciado pelo amigo na aventura da Modernidade, apresentará sempre uma postura crítica em seu relato das façanhas do seu "Príncipe da Grã-ventura". Como Sancho (do Dom Quixote), segue amorosamente o mestre sem, no entanto, deixar-se levar por seus delírios.

\footnotetext{
${ }^{9}$ QUEIROZ, 1978. p. 21.

${ }^{10}$ QUEIROZ, 1978. p. 31.

${ }^{11}$ QUEIROZ, 1978. p. 76.
} 
Por este distanciamento terá a capacidade de perceber a quê os excessos de civilização irão reduzir o Jacinto que, sempre sedento, emagrece a olhos vistos e se entedia em grau diretamente proporcional à variedade de novidades com que se depara.

Jacinto fenece em meio às mundanidades de uma amante compartilhada, o financiamento de uma cortesã por razões meramente sociais e a superficialidade de sua vida, objetos e relações em geral.

No decorrer da narrativa suas desventuras darão ao amigo serrano a oportunidade sempre de demonstrar a precariedade do racionalismo citadino em contraposição ao relativo sucesso do empirismo serrano. Assim, Jacinto será vencido pelos elementos da natureza, que ignora, como no episódio em que a água encanada e aquecida resolve se rebelar "por um desses brutos e revoltos terrores como só os produz a ferocidade dos elementos", ${ }^{12}$ como explica o Zé Fernandes. Logo após será a vez da luz elétrica, episódio que nos é relatado de maneira deliciosa pelo serrano que, mais uma vez, se safa

Na minha imensa desconfiança daquelas forças universais, pulei logo para a porta, tropeçando nas trevas, ganindo um Aqui del-rei! (...) [enquanto ] Jacinto em cima berrava, com o manicuro agarrado aos pijamas. (negrito do autor) $)^{13}$

Através da aparente ingenuidade da narrativa de tais acontecimentos - narrados sempre em tom jocoso, e que evidenciam a facilidade com que o caipira se safa das armadilhas da civilização, fatais para os civilizados como Jacinto -, percebe-se um triste diagnóstico dos (des)caminhos da humanidade guiada pela Modernidade e a subjacente proposta de uma salvação tecnopastoral (para citarmos termos bermannianos) em que se conciliem campo e civilização.

Afinal o Jacinto está a murchar, como nos descreve Zé Fernandes

E nunca o meu Príncipe (...) me pareceu tão corcovado, tão minguado, como gasto por uma lima que desde muito o andasse fundamente limando. Assim viera findar, desfeita em civilização, naquele superrequintado magricela sem músculo e sem energia, a raça fortíssima dos Jacintos! (...) E agora, ali estava aquele último Jacinto, um Jacintículo,

\footnotetext{
${ }^{12}$ QUEIROZ, 1978. p.27.

${ }^{13}$ QUEIROZ, 1978. p. 33.
} 
com a macia pele embebida em aromas, a curta alma enrodilhada em filosofias, travado e suspirando baixinho na miúda indecisão de viver. (negrito do autor) ${ }^{14}$

Para sua redenção concorrerão o destino e o amigo serrano.

Contra uma tal perspectiva de vida estéril, essa da cidade - lugar da super-civilização e da desumanização, onde os homens se regem por "Dois impulsos únicos, correspondendo a duas funções únicas, (...) os dois apetites da cidade: encher a bôlsa, saciar o corpo". ${ }^{15}$ - o autor nos propõe o campo: as Serras. Lá Jacinto e, por extensão, toda a humanidade, reencontrará a oportunidade de viver plenamente.

\section{As serras}

As Serras (portuguesas) são enaltecidas como o território mítico onde estão enterrados os antepassados e onde a vida humana ainda é um valor essencial. Portanto, nada mais natural que a partida do Jacinto para lá, sob o pretexto de trasladação dos restos dos antepassados. Este fato torna-se simbólico, pois a nova morada dos mortos, coincide com a mudança que ocorrerá na vida do descendente, pretextando-a.

O jovem citadino conhece, assim, uma nova forma de vida, menos "civilizada" e mais humana nas Serras portuguesas onde, segundo o Zé Fernandes

Nunca se necessitava de sutileza ou de engenho, e a vida se desenrolava com a segurança imutável com que cada manhã sempre igual o sol nascia, e sempre os centeios e os milhos, regados por águas iguais, seguramente medravam, espigavam, amadureciam. ${ }^{16}$

Nesse encontro deslumbrado com a natureza em estado pujante, Jacinto recuperará a "seiva da vida". E ao reconstituir-se, buscará também uma nova ordem, em que se conciliem o Jacinto urbano e este novo, rural, sem que haja porém uma tentativa de fuga ingênua. A conciliação entre o progresso necessário e a riqueza da vida no campo serão a realização de Jacinto.

\footnotetext{
${ }^{14}$ QUEIROZ, 1978. p. 84.

${ }^{15}$ QUEIROZ, 1978. p. 179.

${ }^{16}$ QUEIROZ, 1978. p. 136.
} 
Num primeiro momento, Jacinto se deslumbra. A natureza lhe parece majestosa, retornam-lhe os instintos de fome e sede, num lugar onde encontra com que saciá-las. Despede-se do tédio, por fim e do eterno cansaço.

Delicia-se, em fase de enamoramento, com as maravilhas da natureza e planeja, como dantes, idéias sonhadoras de transporte de civilização para o campo. Vive, "deixando de ser uma mera sombra andando entre realidades" ${ }^{17}$ nos dizeres do amigo serrano.

Curiosa porém, e bastante reveladora é a aproximação de Jacinto com os habitantes serranos. Numa confirmação da sobriedade dos valores da terra, a riqueza de Jacinto então, não lhe abrirá magicamente as portas, como costumava acontecer em Paris. Como descendente de monarquista, seu retorno traz desconfiança sobre seus anseios políticos e o refinamento de sua pessoa e de suas aventuras parisienses, longe de atrair curiosidade da boa sociedade do lugar, tornam-se fator de segregação.

A veracidade das relações humanas nesse lugar só levam a um maravilhamento o Jacinto, que se percebe como indivíduo, herdeiro de uma herança cultural e familiar.

O encontro de Jacinto com a pobreza de seus subordinados e com a precariedade das condições de produção do lugar finalizam a transformação. Ao perceber a responsabilidade sua para com pessoas e a terra que dependem de suas decisões, surgirá um Jacinto "revolucionário" e, conseqüente, atarefado nas coisas da terra, e na ajuda aos seus agregados.

Vivendo enfim uma "reconciliação com a Natureza, e a renúncia às mentiras da civilização", ${ }^{18}$ Jacinto irá brotar.

Começará por buscar uma melhor distribuição de renda para seus trabalhadores quando descobre, chocado, que há fome e miséria no seu paraíso. Para eles, tanto quanto para todos aqueles acostumados à ordem imutável do campo, ele traz a "revoluçâo", enquanto insere de maneira positiva, no vocabulário de muitos, uma palavra estranha, que aprendem a estimar pelo fruto de seus esforços: o "Socialismo".

Entrementes Jacinto instala telefones, assistência médica e decidese por utilizar os poderes pedagógicos de uma novidade: a lanterna mágica. Há uma semente de Modernidade neste processo: gradualmente

${ }^{17}$ QUEIROZ, 1978. p.138

${ }^{18}$ QUEIROZ, 1978. p. 150 
Jacinto instaura um processo que revoluciona certamente as Serras. Mas esta revolução tem seus limites. Jacinto se encontra maduro e cônscio da necessidade de usar a tecnologia sem ser usado por ela.

Jacinto casa-se e tem filhos. E enquanto enraíza-se nas Serras, adia eternamente um retorno a Paris, que jamais se realizará. A cargo do Zé Fernandes ficará este retorno final à civilização, para um definitivo repúdio: "O que tens de bom, que é o teu gênio, elegante e claro, lá o receberei pelo correio." ${ }^{\prime 19}$ Este o derradeiro escarro na face da cidade.

\section{4. $O$ repouso do guerreiro}

A viagem de Zé Fernandes a Paris é o fecho necessário à aventura. Seria extremamente perigoso para Jacinto um retorno a "Circe" deixando sua "Penélope" Serrana. Mas havia que encerrar a narrativa com a comparação definitiva e vitória final das Serras sobre a cidade.

Para isso, o Zé Fernandes volta a Paris e nos apresenta a imutabilidade do processo civilizado. O redemoinho que aparentemente, move a vida das pessoas, deixando-as sempre no mesmo lugar. Ele nos levará ao reencontro de todos os personagens lá deixados, e que permanecem ainda em seu inútil "dolce far niente".

Em contraposição cabal à revolução promovida por Jacinto em sua vida e na daqueles que o cercavam, a cidade e seus habitantes continuam alardeando sua inútil futilidade, como nos demonstra um reclame que se destaca aos olhos do Zé Fernandes.

Um enorme cartaz em que uma mulher nua, com flores bacânticas nas tranças, se estorcia, segurando numa das mãos uma garrafa espumante, e brandindo na outra, para o anunciar ao mundo, um novo modêlo de saca-rôlhas. ${ }^{20}$

Tal imagem nos dirige de forma cabal ao cerne da questão: Eça nos destaca, para além dos avanços científicos, uma Modernidade representada grotescamente por uma sensualidade gratuita, imprensa na forma mais fugaz, o cartaz, onde se vê uma mulher desnecessariamente desnudada,

\footnotetext{
${ }^{19}$ QUEIROZ, 1978. p. 184.

${ }^{20}$ QUEIROZ, 1978. p. 184
} 
enquanto espoca um champanhe fortuito, propalando a sublime de um novo saca-rolhas. Ora, encontram-se aí, em curtas e vigorosas pinceladas, um quadro revelador dos aspectos que originaram a obra, como libelo contra a efemeridade e vazio da Modernidade, sua fugacidade, a sensualidade grotesca e a superficialidade do culto à novidade.

O conservadorismo de uma tal perspectiva não deve obscurecer a agudeza da observação. A proposição de retorno à tradição, nos moldes que neste livro se apresentam, seria revolucionária em sua época, e queremos crer que ainda encontre ecos em nossos dias.

Não é a busca do "Paraíso Perdido" a proposta de Eça. Por sinal, ingenuidade não seria uma característica a ser-lhe imputada. Coerente, cônscio de sua posição e da realidade que o cercava, não dirigia sua crítica à tecnologia, - que, por sinal, Jacinto levaria para o campo, com ressalvas - mas sim contra o vazio de uma Modernidade obtusa e em muitos casos obsoleta, por não ser capaz de satisfazer as necessidades mais elementares do ser humano, enquanto instiga incessantemente seu apetite por veleidades que o esterilizam. Uma tal perspectiva se encontra atualíssima, sendo mote de algumas das mais consistentes críticas Pós-modernas atuais.

Eça, portanto, indo muito além da crítica magoada de boa parte dos anti-modernos românticos do XIX, previa, de forma consistente um quadro triste e futurista do momento em que a Modernidade se depararia com o esvaziamento de seu sentido de salvação perdendo, assim, a capacidade de guiar as almas para algo que não fosse um grande vazio.

Interessantíssimo se torna, para nós este encontro entre o tradicionalismo anti-moderno expresso na obra e a convergência deste para com posturas Pós-modernas de nossa atualidade. Encontra-se aí, o toque de gênio. Uma tal postura aparentemente reacionária, decorridos cem anos, se encontra mais que atual pela argúcia da crítica queiroziana.

Tomar a experiência de Jacinto ao pé da letra, em nossos dias seria, uma aposta no fracasso. Não há hoje como repetir Thoureau, ${ }^{21}$ ou mesmo o Jacinto, simplesmente porque aquelas Serras virgens já não existem. Explicita-se o anacronismo dialético de uma tal perspectiva, quando vemos a juventude neoagrária e cosmopolita em suas roupas de "caubói", ao som

${ }^{21}$ Referimo-nos aqui ao poeta romântico americano que, decidido a retornar à natureza, abandonou toda forma de conforto e retornou literalmente a ela, vivendo de maneira bastante rudimentar por dois anos. 
da música "country" nacional, orgulhosíssima por sua postura caipira em meio a um rodeio em Ribeirão Preto. Acreditamos que se trate de uma das vertentes "naif" do tecnopastoralismo de que nos fala Bermann.

Eça não apresentou, de maneira alguma, ingenuidade em suas propostas. Apesar do arcaísmo de suas críticas à luz elétrica e à água encanada, que hoje são realidades insofismáveis, sua crítica validou-se com o passar do tempo: claro hoje nos parece o ridículo do consumismo exacerbado que se tornou marca registrada de nossa época, em que se acumulam inutilidades nos anúncios e nas residências.

Não temos a felicidade de poder repetir a trajetória de Jacinto, encontrando a paz na ruralidade ancestral e sadia de seus domínios. Mas a fórmula jacíntica de felicidade a isso não se reduz, sendo esta a pérola da obra, em nossa opinião: não é o campo que traz luz a Jacinto mas o encontro com seus semelhantes. É na compreensão de sua responsabilidade social e comunitária, principalmente, que ele encontra o sentido da vida. No encontro com a essência do humano, que para além da tecnologia se acha no humano e em suas manifestações mais cabais, como a literatura e o convívio social; é na busca de si e do outro que Jacinto finalmente se encontra.

Eça nos propõe um humanismo sem ilusões, mas ainda pleno de significados. Contra o tecnologismo dogmático que minimiza o humano Eça propõe um humanismo que, contrariando os imperativos de uma supercivilização, reifica a natureza como habitat humano e submete a Modernidade ao serviço de si e de seus semelhantes.

\section{Referências Bibliográficas}

BERMAN, Marshall. Tudo que é sólido desmancha no ar: a aventura da modernidade. $7^{\underline{a}}$ reimpressão. São Paulo: Companhia das Letras, 1989.

QUEIROZ, Eça de. A cidade e as serras. São Paulo: Clube do Livro, 1978.

MARX, Karl. Speech at the anniversary of the People's Paper. In. The MarxEngels Reader. 2. ed. (Norton, 1978). 


\section{Resumo}

Em tempos de Pós-modernidade presumida e de uma já desgastada experiência anti-Moderna, A Cidade e as Serras, de Eça de Queiroz representa, em nossa opinião, uma maneira de rever a Modernidade através do olhar de um detrator contemporâneo a ela.

A partir dos conceitos de Marshall Bermann (Modernidade e Pós Modernidade), pretendemos poder perceber, na crítica queiroziana à Modernidade, uma possibilidade de descentralização, problematização e reconhecimento, na eterna busca de novas respostas para esta que - como nos dá a perceber o texto queiroziano - é já uma velha questão.

\section{Abstract}

In these times of presumed Post Modernity and anti-modernist experience, Eça de Queiroz's A Cidade e as Serras represents, in our opinion, a way of looking back at Modernity through eyes of a contemporary opponent of Modernity.

Using Marshall Berman's concepts (Modernity and Post-Modernity), we hope to have identified - in Queiroz's critiques of Modernity - a way of de-centralising our eyesight and a possibility of recognising and problematizing in the quest for new answers to a question which, as Queiroz's text shows, is an older one. 